\title{
Correction to: Expression of Concern: Knockdown of elF3d inhibits cell proliferation through G2/M phase arrest in non-small cell lung cancer
}

\author{
Zhifeng Lin ${ }^{1} \cdot$ Liwen Xiong ${ }^{2} \cdot$ Qiang Lin ${ }^{1}$
}

Published online: 3 May 2019

(c) Springer Science+Business Media, LLC, part of Springer Nature 2019

Correction to: Medical Oncology (2018) 35:130 https://doi.org/10.1007/s12032-018-1178-4

The original version of this article contained an error in the shRNA sequence. The correct shRNA sequence should read as "TTCTCCGAACGTGTCACGTCTCGAGACGTGACA CGTTCGGAGAATTTTT".

Publisher's Note Springer Nature remains neutral with regard to jurisdictional claims in published maps and institutional affiliations.

The original article can be found online at https://doi.org/10.1007/ s12032-018-1178-4.

\section{Qiang Lin}

LinqiangPhD@163.com

1 Department of Thoracic Surgery, Shanghai First People's Hospital, Shanghai Jiaotong University, No. 100 HaiNing Road, Shanghai 200080, China

2 Department of Pulmonary, Shanghai Chest Hospital, Shanghai Jiaotong University, 241 West Huaihai Road, Shanghai 200030, China 